\title{
Truncus arteriosus with double aortic arch: A rare association
}

\author{
Selman Vefa Yıldırım ${ }^{1}$, Ali Yıldırım² \\ ${ }^{1}$ Department of Pediatric Cardiology, Near East University Medical Faculty, Nicosia, Cyprus; ${ }^{2}$ Department of Pediatric \\ Cardiology, Eskisehir Osmangazi University Medical Faculty, Eskisehir, Turkey. \\ Email: svefay@yahoo.com \\ Received: 25th July 2016, Revised: 26th September 2016, Accepted: 9th May 2017
}

\begin{abstract}
SUMMARY: Yıldırım SV, Yıldırım A. Truncus arteriosus with double aortic arch: A rare association. Turk J Pediatr 2017; 59: 221-223.

Truncus arteriosus (TA) is a congenital heart defect often diagnosed in neonatal period; it represents $0.7 \%$ of all congenital heart lesions. The pulmonary arteries originate generally above the coronary ostium. Aorto-pulmonary and interventricular defects are believed to represent an abnormality of conotruncal septation. TA is classified into four types, according to Van Praagh and Colette Edwards. Some of congenital heart defects may be associated with TA, such as aortic interruption. In literature, TA with a double aortic arch is observed as a very rare condition. We present here a newborn diagnosed with a combination of TA type 1 and double aortic arch.
\end{abstract}

Key words: neonate, truncus arteriosus, double aortic arch.

Truncus arteriosus is an uncommon congenital heart defect that is characterized by a single arterial vessel arising from the ventricles with single semilunar valve. The incidence of defect is 6-10/100,000 live births, representing only $0.7 \%$ of all congenital heart lesions ${ }^{1}$. Anatomically, a single great artery arising from the base of the heart supplies the aorta, pulmonary arteries and coronary arteries. The anomaly is the result of incomplete septation of the embryonic truncus. The developmental arrest occurs around the 32nd day of embryological development. Truncal vessel receives the blood of both ventricles. In similar cases, truncal vessel may originate completely from the right or left ventricle. The pulmonary arteries originate from this vessel generally above the coronary ostium. Truncus arteriosus straddles a defect in the outlet portion of the interventricular septum. Aortopulmonary and interventricular defects are believed to represent an abnormality of conotruncal septation. Because the systemic and pulmonary flow originates from the common trunk, ductus arteriosus is not required to support the fetal circulation. Therefore, in those patients with a normal caliber aortic arch, the ductus arteriosus is either absent or diminutive. This disease is classified into four types, according to Van Praagh and Colette
Edwards. Various congenital heart defects may be associated with truncus arteriosus, some of which may have an impact on treatment. In literature research, truncus arteriosus with a double aortic arch is observed as a very rare condition $^{2-7}$. We present hereby a newborn diagnosed with the combination of truncus arteriosus and double aortic arch.

\section{Case Report}

Three-days old, 2,580 g term girl baby was referred to Şanlıurfa Children Hospital, with rapid breathing and cyanosis. She was suspected to suffer from truncus arteriosus or ventricular septal defect and pulmonary atresia after her cardiac examination. General condition of patient was poor and she was intubated. The oxygen saturation was $75 \%$. Dysmorphic appearance (short neck, low-set ears, flat nasal root, cleft palate, excessive growth of hair on the forehead) was observed (Fig. 1). There was edema of the eyes and limbs. There was a $2 / 6$ systolic murmur at the left lower sternal border. Echocardiographic evaluation also revealed normal visceroatrial situs, levocardia, normal ventricular relations and small left ventricle with hypoplastic mitral valve. In addition, large outlet ventricular septal defect and only one arterial trunk with a non-stenotic and 


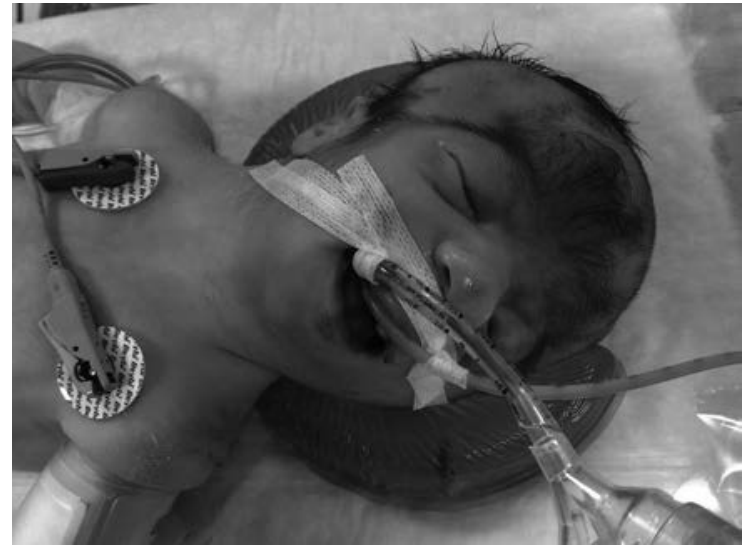

Fig. 1. Dysmorphic appearance of patient.

nonregurgitant valve were detected. Above the truncal valve, a short main pulmonary artery originated from the posterior aspect of the trunk and bifurcated into the right and left pulmonary arteries. There was no ductus arteriosus. She was suspected to have truncus arteriosus type 1 with right aortic arch and arch anomaly. On the angiogram, she was observed to have type 1 truncus arteriosus with double aortic arch (Fig. 2a and b), right atrium mean pressure was $8 \mathrm{~mm} \mathrm{Hg}$ and right ventricle systolic pressure was $90 \mathrm{~mm} \mathrm{Hg}$. Chromosomal analysis was normal; FISH analysis was negative. Two days later the patient died due to severe heart failure and septicemia.

An informed consent was received from the family to present the patient in any medical platform.

\section{Discussion}

Truncus arteriosus is characterized by a single arterial vessel arising from the ventricles with single semilunar valve. Systemic, pulmonary and coronary blood supplies are provided from this common trunk. The disease usually is diagnosed during the newborn period. There is congestive heart failure and increased pulmonary vascular resistance caused by increased pulmonary blood flow. Most of the patients without treatment dies in first year of life. A few cases with pulmonary stenosis can reach adulthood ${ }^{8}$.

Various abnormalities may be associated with truncus arteriosus which may have an impact on management and outcome. The aortic arch anomalies with truncus arteriosus vary from a benign right aortic arch to arch interruption. In $10 \%$ of the truncus arteriosus patients interrupted aortic arch is the associated abnormality. Double aortic arch is usually isolated. It is sometimes associated with congenital heart diseases such as tetralogy of Fallot, ventricular septal defect, and transposition of great arteries. The combination of common arterial trunk associated with double aortic arch is very rare. There are nine cases in the literature. Bhan et $\mathrm{al}^{3}$ found double
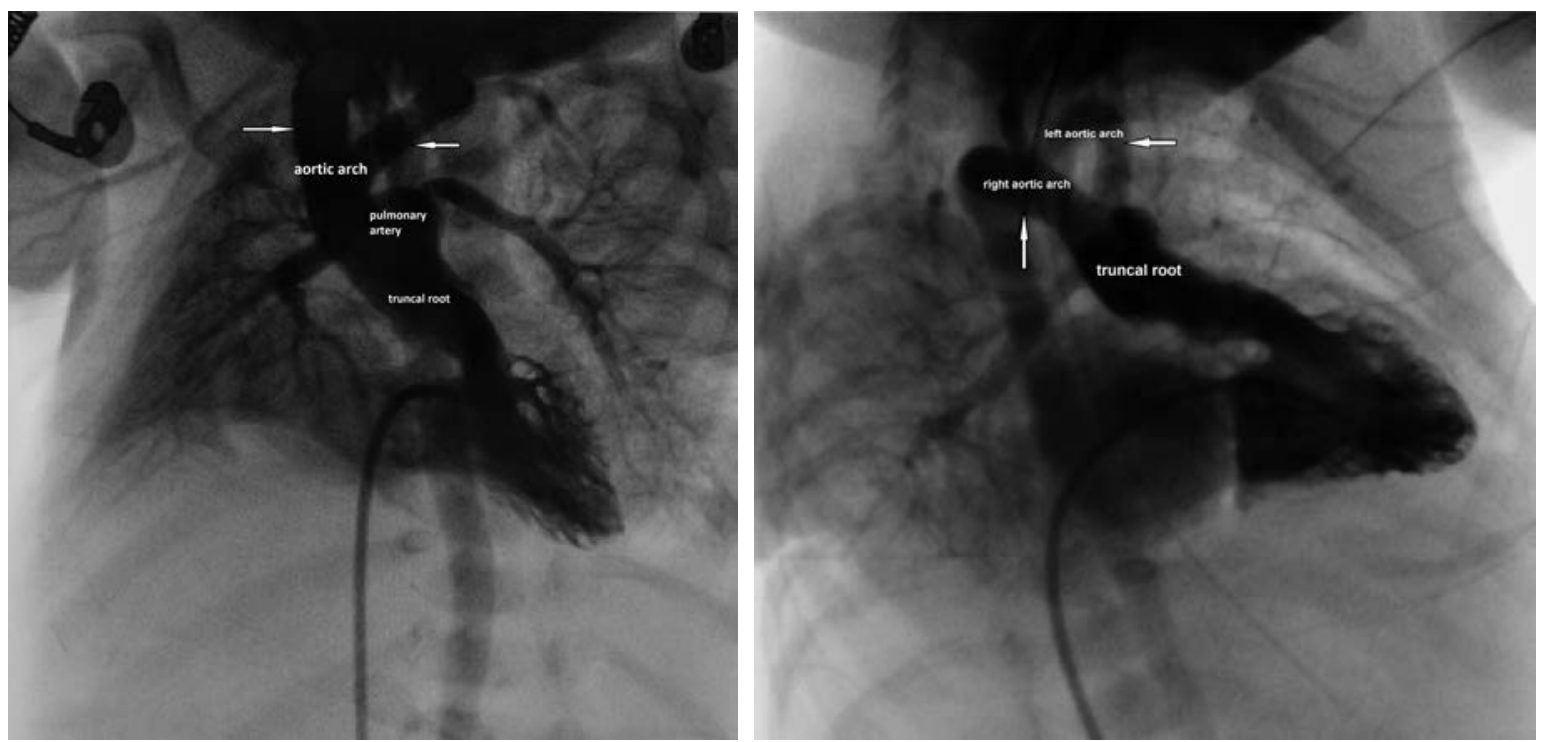

Fig. 2a and 2b. 30 degree cranial with 30 degree left anterior oblique and 30 degree cranial with 30 degree right anterior oblique positions angiograms showed type 1 truncus arteriosus with double aortic arch. 
aortic arch in a truncus arteriosus patient whose breathing problems had not been regressed in postoperative period. Paul et $\mathrm{al}^{5}$ showed the association of truncus arteriosus and double aortic arch in a patient with computerized tomography, and Schreiber et $\mathrm{al}^{6}$ showed the association of truncus arteriosus and double aortic arch as postmortem. In our patient, we found she had an aortic arch anomaly with echocardiography. We performed angiography and diagnosed the double aortic arch with truncus arteriosus. Although echocardiography can show suspicion of the aortic arch anomaly ${ }^{1,7}$. Computed tomography (CT) scan is useful for its definitive diagnosis. Also, the CT scan can show compression of the trachea, bronchus, and esophagus. Imai et $\mathrm{al}^{7}$ found double aortic arch and mitral hypoplasia in a patient with truncus arteriosus. Our case was similar with Imai's report.

Structural abnormalities of the truncal valve are frequently observed and significant truncal valve regurgitation may be present. Coronary artery is usually normal; rarely coronary artery course anomalies are seen. The single coronary artery and an intramural course as the most important variations ${ }^{9}$. Ventricular septal defect is classically subarterial in $80 \%$ of the cases. $20 \%$ of the cases consist of perimembranous defect. $10 \%-20 \%$ of the cases are accompanied by interrupted aortic arch or coarctation. The persistent left superior vena cava is observed with $10 \%$ of the patients. Patent foramen ovale is frequent, atrial septal defect is observed with about $10 \%$ of the cases. Also atrioventricular discordance, situs inversus with dextrocardia, double inlet ventricle, atrioventricular valve stenosis and atresia, hypoplastic left ventricle, atrioventricular canal defect, vascular ring may be accompanied ${ }^{10}$.

In conclusion, aortic arch anomaly should be suspected in a patient with truncus arteriosus. Right-sided aortic arch, interruption of the aortic arch and the double arch must be evaluated carefully in patients with truncus arteriosus.

\section{REFERENCES}

1. Reller MD, Strickland MJ, Riehle-Colarusso T, et al. Prevalence of congenital heart defects in metropolitan Atlanta, 1998-2005. J Pediatr 2008; 153: 807-813.

2. Alboliras ET, Lombardo S, Antillon J. Truncus arteriosus with double aortic arch: two-dimensional and color flow Doppler echocardiographic diagnosis. Am Heart J 1995; 129: 415-417.

3. Bahn A, Gupta M, Kumar MJ, Kothari SS, Gulati GS. Persistent truncus arteriosus with double aortic arch. Pediatr Cardiol 2006; 27: 378-380.

4. Pacileo G, Palma G, Russo MG, Vosa C, Calabro R. Truncus arteriosus and double aortic arch associated with DiGeorge syndrome. Texas Heart Inst J 1991; 18: 206-208.

5. Paul JF, Serraf A. Truncus arteriosus and double aortic arch. Circulation 2002; 105: e170.

6. Schreiber C, Tsang VT, Yates R, Khambadkone S, Ho SY, Anderson RH. Common arterial trunk associated with double aortic arch. Ann Thorac Surg 1999; 68: 1850-1852.

7. Imai K, Tsukuda K, Sakazaki H, Fujiwara K. Persistent truncus arteriosus with double aortic arch and mitral stenosis. Pediatr Cardiol 2013; 34: 2024-2026.

8. Ruan W, Loh YJ, Guo KW, Tan JL. Surgical correction of persistent truncus arteriosus on a 33-year-old male with unilateral pulmonary hypertension from migration of pulmonary artery band. J Cardiothorac Surg 2016; 11: 39.

9. Rodríguez H, Montero H, Fernández A, Guzman A, Di Sessa T. Surgical correction of truncus arteriosus with unusual origin of the right coronary artery. World J Pediatr Congenit Heart Surg 2016; 7: 407-410.

10. Huang SC, Wang CJ, Su WJ, Chu JJ, Hwang MS. The rare association of truncus arteriosus with a cervical double aortic arch presenting with left main bronchial compression. Cardiology 2008; 111: 16-20. 